\title{
Flight Attendants' Emotional Labor and Exhaustion in the Taiwanese Airline Industry
}

\author{
Cheng-Ping CHANG, Ju-Mei CHIU
}

Nan-Tai Street, Yung-Kung City, Taiwan, China

Email: justin@mail.stut.edu.tw

Received May 2, 2009; revised July 29, 2009; accepted August 4, 2009.

\begin{abstract}
Few research studies have discussed the two variables of emotional labor and emotional exhaustion, and even fewer have examined flight attendants as the research subject. The current study employed a questionnaire method to examine 353 Taiwanese flight attendants' feelings about emotional labor, the status of their emotional exhaustion, and the relationship between emotional labor and emotional exhaustion. The research results indicate that: 1) while the degree of emotional labor operating on female flight attendants is on the medium to high side, the attendants' perception of emotional exhaustion is only medium; 2) female flight attendants' emotional labor has a significant positive correlation with their emotional exhaustion; and 3) among the perspectives of emotional labor, the qualities of "deep emotional masking" and "multiformity" have a significant predictive effect on emotional exhaustion.
\end{abstract}

Keywords: Flight Attendant, Emotional Labor, Emotional Exhaustion

\section{Introduction}

In recent years, the industrial structure in Taiwan has changed such that the service industry has gradually replaced traditional manufacturing as the leading industry. Statistical data reported in the Quarterly National Economic Trends issued by the Directorate-General of Budget, Accounting and Statistics, Executive Yuan, indicated that in the third quarter of 2006 the service industry accounted for $71.98 \%$ of the country's industry.

The airline industry has been part of the service industry since the government implemented the open sky policy of airline deregulation in 1987. As a result, many private airlines entered the market (Liou, 2006). High speed rail opened completely to traffic in 2007, taking away many passengers from airlines in western Taiwan. Understanding that a low price strategy cannot maintain passenger loyalty for any length of time, the airlines have changed their strategy to emphasize improved quality of service and maintenance of flight safety. These strategies encourage passengers to maintain a positive opinion about the airlines and to appreciate the quality of service they provide.

Flight attendants constitute the majority of customerservice employees in the airline industry. Compared to their colleagues in other departments, flight attendants have more contact with passengers, and for longer periods of time. Within the airline industry, flight attendants are referred to as the first-line service attendants [1]. Passengers' images of the airlines are heavily influenced by the manners and emotional attitudes of flight attendants. The working environment of flight attendants is noteworthy in that, over time, it will have a negative impact on flight attendants' psychological health. During international service, flight attendants face numerous stresses. They must provide service over a long period of time; the pressure in the aircraft cabin is high and the space is hermetic; the types and temperaments of passengers are complex; and the environment may foster various diseases. Furthermore, the work hours of flight attendants are uncertain, and they often deal with night-shift assignments and time-zone changes. Such anomalous shifts over a long period of time constitute the main influence on the health of flight attendants. Beh \& McLaughlin [2] suggested that stress experienced during long flights affects some aspects of mental performance. In addition, the uncertainty of flight attendants' work schedules limits their private time, potentially causing conflicts between work and family. Additionally, an overly-heavy workload may induce burnout among flight attendants. Such burnout, in turn, increases flight attendants' alienation from work and decrease their sense of connection to the company. Liang \& Hsieh [3] suggested a relationship between burnout and workplace deviance, identified as a component of job performance. Too much 
physiological and psychological stress over a long period of time causes lower service quality and a higher turnover rate.

Flight attendants have to control their overt behavior and private emotions in order to maintain positive interactions with colleagues and passengers. This kind of emotional control is dictated by the job performance rules of the company, and attendants are required to adjust their emotions to the requirements of the job. This is precisely how Hochschild [4] defined "emotional labor." Engaging in emotional labor over an extended period may cause emotional labor overload and make adjustment to work demands difficult. This situation, in turn, may lead to emotional dissonance, that is, a conflict between the attendant's internal emotions and the organization's rules regarding emotional expression. Over an extended period, this may have a negative effect on the employee's physiology and psychology. Long-term emotional stress and relatively intense emotional labor result in emotional exhaustion. (see Figure 1)

There have been few research studies on emotional labor among Taiwanese flight attendants. This research focuses on flight attendants in Taiwan, addressing their experiences of emotional labor and emotional exhaustion. The goal of this study was to develop suggestions for additional research, provide practical advice for airlines and related management organizations about the management of flight attendants' emotional labor, and help those in the flight attendant industry better understand the work characteristics of that role. The research objectives are as follows:

1) To understand the status of flight attendants' emotional labor and emotional exhaustion.

2) To examine differences in emotional labor and emotional exhaustion among flight attendants from different backgrounds.

3) To explore the relationship between emotional labor and emotional exhaustion among flight attendants.

4) To understand whether flight attendants' emotional labor predicts emotional exhaustion.

\subsection{Emotional Labor}

The concept of emotional labor was first proposed by Hochschild [4]. She described emotional labor as follows: "Attendants who are in contact with clients over an extended period are required to control their emotions

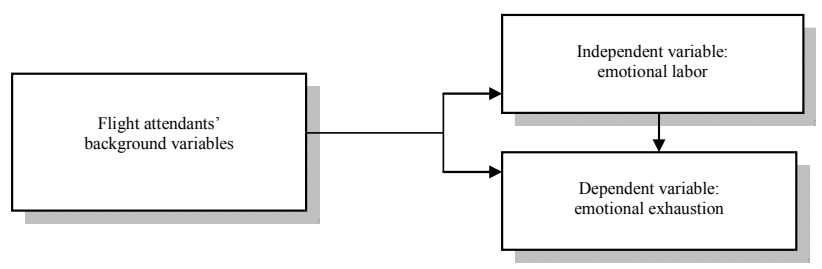

Figure 1. Research framework during work time and to display appropriate facial expressions and behaviors. At the same time, the organizations' regulations and salary structure require that these attendants control their emotions to create the work climate that the organization wants." In order to meet the organization's expectations for client service, most employees must frequently control their own emotions in such a way as to convey the emotion expected by the organization.

Referring to the Hochschild's [4] model of emotional labor, Wharton [5] proposed three work characteristics or perspectives:

1) The worker has ongoing contact with the public in both face to face and conversational exchanges.

2) When working, the employee is expected to express certain emotions that will have the desired influence on others.

3) The range of acceptable emotional expressions is limited by employer-imposed regulations.

Goffman [6] argued that the form of emotional expression imposed by emotional labor amounted to surface acting. Goffman suggested that emotional labor amounts to a dramatic enactment, one similar to that of an actor who is expected to express emotion in a screenplay. Goffman [6] also posited that, in addition to surface acting, workers may choose to modify how they think about their own feelings or to resist conforming to the emotional expression as dictated by the external organization. Goffman's model of emotional labor as drama su- ggests that employees may also adopt "deep acting".

Earlier researchers discussed emotional labor from the perspectives of high- and low-level emotional labor as proposed by Hochschild [4]. Discussion about these two levels, however, does not completely address the emotional labor load and its component factors. The four perspectives proposed by Morris and Feldman [7] lacked the support of empirical research. A test of Morris and Feldman's [8] approach discovered that, although their model held promise for explaining the capacity for emotional labor, it was unable to differentiate causality from correlation in explaining emotional labor and its consequences.

Long-term emotional stress or an environment laden with too much emotional labor may cause emotional exhaustion, another consequence of emotional labor. When employees have contact with clients for a long time, the heavy emotional load may induce energy exhaustion [9]. This may cause employees to withdraw from their duties and may lead to illness $[10,11]$.

\subsection{Emotional Exhaustion}

According to the literature on work burnout, the first phase of work burnout is emotional exhaustion [12]. Emotional exhaustion occurs when individuals lack energy and have the sense that they are becoming exhausted 
[10]. Saxton, Phillips, and Blakeney [9] also pointed out that emotional exhaustion is related to excessive emotional demand during interpersonal interaction; this causes energy exhaustion and increased withdrawal. These conditions decrease productivity and increase certain stress reactions. In the same vein, Maslach and Jackson [13] found that workers who had to engage in face to face contact with clients as well as manage emotional expression for extended periods were most susceptible to emotional exhaustion.

Based on these findings, it seems probable that flight attendants develop emotional exhaustion as a result of frequent and extended interactions with customers. Those who experience excessive interaction with the clients or who obey the organization's expectations for emotional control [14] show increasingly frequent emotional exhaustion.

Emotional exhaustion harms an individual's body and mind as well as the organization. On the psychological level, emotional exhaustion leads to lower self-esteem, depression, nervousness, and irritability. On the physiological level, individuals might experience headaches, insomnia, stomach upset, and so on [15].

\section{Method}

\subsection{Sample and Procedure}

The current research focused on first-line employees, i.e., flight attendants, employed by domestic and international airlines in Taiwan (Far Eastern Air Transport Corp., Mandarin Airlines, UNI Ai, TransAsia Airways, EVA Air, and China Airlines). We distributed 500 questionnaires and received 380 responses. After eliminating defective questionnaires, we were left with 353 questionnaires, for an effective response rate of $70.16 \%$. Because of time and resource limitations as well as the work characteristics of flight attendants and their variable schedules, we delivered the questionnaires to selected senior flight attendants and asked them to transmit the questionnaires to other attendants working for national and international airlines through their own company and other companies. We also asked these flight attendants to complete the questionnaire when they were on duty. Because the work time and airline schedules of flight attendants are not fixed, and because the shift schedules are arranged by computer, flight attendants are subject to arbitrary posting by the airline that trained them. Therefore, each flight attendant may work with a different flight team at any given time and may work with the same flight team over the short term only rarely. Thus, we provided the questionnaires without knowledge of which flight attendants would receive them. Therefore, this sampling method amounts to simple random sampling.

\subsection{Hypotheses}

H1: Flight attendants with different backgrounds have significantly different feelings about emotional labor.

H2: Flight attendants with different backgrounds have significantly different feelings about emotional exhaustion.

H3: Flight attendants' emotional labor is positively correlated with emotional exhaustion.

H4: Flight attendants' emotional labor is predictive of emotional exhaustion.

\subsection{Measures}

\subsubsection{Emotional Labor}

Scale development: The first part of the emotional labor scale, cited as the "Organization Emotional Labor Scale" developed by Lin [16] especially for Taiwan, measures emotional labor. It adopts a 5-point Likert scale to score the items from 1 to 5 as absolute disagreement, disagreement, neutral, agreement, and absolute agreement, respectively. The higher the total score, the greater the employee's level of emotional labor. The original emotional labor scale had 24 questions divided into five themes: basic emotional expression, surface acting, deep acting, multiformity, and interpersonal interaction. Taking into account the test of professional validation as well as suggestions by experts, the descriptions of two questions in the original scale were modified. Finally, the authors designed the pre-questionnaire. Using SPSS, the authors conducted an item analysis on responses to the pre-questionnaire designed to test the scale questions. This research will adopt, as indices of internal consistency, the criterion method of discrimination analysis and correlative analysis on questions and the total score on a test of isomorphism type to analyze the pre-questionnaire.

Scale reliability and validation analysis: Analysis of the internal consistency of question 16 showed that the correlation coefficient of items and total scores was lower than 0.3 and that the discrimination was unacceptably low. Therefore, we deleted this question. The discrimination values of Question 15 and Question 17 were low, and they did achieve the level of significance. Therefore, the descriptions of these two questions were modified. Based on the item analysis, the emotional labor scale retained 23 questions. Cronbach's $\alpha$ calculated for the entire emotional labor scale was 0.883 , and the reliability the entire scale achieves was over 0.7 . The reliability value of the themes within the scale was calculated at 0.6 , which is within the acceptable range. These results demonstrated the reliability of this emotional labor scale.

\subsubsection{Emotional Exhaustion}

Development of scale: The second part of the emotional exhaustion scale cites the third edition of the Maschlach Burnout Inventory-General Survey (MBI-GS) developed by Maslach and Leiter [17]. There are five questions in this scale. This research adopts a 5-point Likert scale to score the items from 1 to 5 as absolute disagreement, 
disagreement, neutrality, agreement, and absolute agreement, respectively. The higher the total score, the higher the degree of emotional exhaustion an employee feels. The original scale was tested by expert validation and we retained all six terms to develop the pre-questionnaire by referring to the experts' suggestions.

Scale reliability and validation analysis: Referring to the item analysis results, the correlations of all questions and the subscale of emotional exhaustion scale were above 0.3 , achieving significance. In addition, the critical ratios were higher than 3 and achieved significance. Therefore, the five questions of the emotional exhaustion scale are all retained, in keeping with results of the item analysis. The Cronbach's $\alpha$ for the entire emotional exhaustion scale was 0.755 , and the reliability of the entire scale was more than 0.7 . Both are in the acceptable range, indicating that this emotional exhaustion scale is reliable.

\section{Results}

The effective sample of flight attendants was 353 respondents. The demographic data were as follows: Age: One hundred twelve flight attendants were 31-35 years old, accounting for $31.7 \%$ of the sample. Marital status: Two hundred attendants were single, accounting for $56.7 \%$ of the sample. Educational background: One hundred seventy-one attendants had graduated from junior college, accounting for $48.4 \%$ of the sample. Service year: One hundred eighty-four attendants had served for three to seven years, accounting for $51.1 \%$ of the sample. Average salary: One hundred sixty-two flight attendants reported salaries ranging from NTD60,000 to NDT 70,000 , accounting for $45.9 \%$ of the sample. The data regarding flight attendants' emotional labor and emotional exhaustion are displayed in Table 1

There were 23 questions on the emotional labor scale. Results showed an average emotional labor score of 4.15 $(S D=0.392)$ on the 5 -point Likert scale; the average score is thus moderately high. This indicates that the flight attendants believe that they must obey the company's regulations regarding their emotional expression while working. Results indicate that these flight attendants engaged in a high level of emotional labor. Analyses of each element of emotional labor indicated that interpersonal interaction scored highest on the emotional labor scale $(M=4.39, S D=0.569)$; next highest was basic emotional expression $(M=4.28, S D=0.482)$; multiformity achieved the lowest score $(M=3.66, S D=0.642)$. There were five questions on the emotional exhaustion scale. The average score over all questions was $3.81(S D=.528)$. This result indicates that the feeling of exhaustion experienced by flight attendants in response to emotional labor is moderately high.

The current study examined whether different backgrounds cause differences in feelings about emotional labor. Background variables included age, marital status, educational background, service year, and average salary. Results are displayed in Table 2:

Age: Flight attendants of different ages showed significant differences in their perspectives on emotional labor. According to the post hoc analysis using Scheffe's test, feelings regarding surface acting were experienced more strongly by flight attendants $20-25$ years of age, and those older than 41 , than by those $26-30$.years old. Feelings about deep acting were stronger among attendants 20-25 years old, 31-35 years old, and older than 41 years old than among those 26-30 years old. Feelings of multiformity were more profound among flight attendants 31-35 years old than among 36-40 year-old attendants. The degree of emotional exhaustion of flight attendants 36-40 years old was more pronounced than that among those 20-30 years old. In addition, feelings of emotional exhaustion were stronger among flight attendants 31-35 years old than among attendants 20-25 years old. And, finally, flight attendants older than 41 years had the strongest feelings about emotional exhaustion.

Table 1. Abstraction of the analysis on domestic flight attendants' emotional labor and emotional exhaustion measured on a 5-point Likert scale $(\mathrm{N}=353)$

\begin{tabular}{|c|c|c|c|c|c|}
\hline Name & $\begin{array}{l}\text { Number of } \\
\text { Questions }\end{array}$ & Minimal Value & Maximal Value & Average of Question & $\begin{array}{c}\text { Standard Deviation } \\
\text { of Question }\end{array}$ \\
\hline Entire Emotional Labor & 23 & 2.96 & 5.00 & 4.15 & 0.392 \\
\hline Basic Emotional Expression & 7 & 2.86 & 5.00 & 4.28 & 0.482 \\
\hline Surface Acting & 3 & 2.33 & 5.00 & 4.13 & 0.598 \\
\hline Deep Acting & 7 & 2.71 & 5.00 & 4.15 & 0.531 \\
\hline Multiformity & 3 & 1.67 & 5.00 & 3.66 & 0.642 \\
\hline Interaction & 3 & 3.00 & 5.00 & 4.39 & 0.569 \\
\hline Entire Emotional Exhaustion & 5 & 2.80 & 5.00 & 3.81 & 0.528 \\
\hline
\end{tabular}


Table 2. Analysis of the difference between the basic attribute of research object and research variable $(n=353)$

\begin{tabular}{lccccc}
\hline \multicolumn{1}{c}{ Item } & $\begin{array}{c}\text { Age } \\
\text { (F Value) }\end{array}$ & $\begin{array}{c}\text { Marital Status } \\
\text { (F Value) }\end{array}$ & $\begin{array}{c}\text { Educational Background } \\
\text { (F Value) }\end{array}$ & $\begin{array}{c}\text { Service Year } \\
\text { (F Value) }\end{array}$ & $\begin{array}{c}\text { Average Salary } \\
\text { (F Value) }\end{array}$ \\
\hline Entire Emotional Labor & $4.004^{*}$ & 2.445 & 0.531 & 2.248 & $2.928^{*}$ \\
Basic Emotional Expression & 0.771 & 1.621 & 0.527 & 1.729 & $3.776^{* *}$ \\
Surface Acting & $4.868^{* *}$ & 0.462 & 1.011 & $2.780^{*}$ & $4.745^{*}$ \\
Deep Acting & $9.083^{* * *}$ & $4.928^{* *}$ & 0.204 & $3.071^{*}$ & $2.636^{*}$ \\
Multiformity & $3.119^{*}$ & 0.290 & 2.620 & 1.552 & 0.798 \\
Interaction & 2.120 & $3.180^{*}$ & 0.454 & $3.441^{*}$ & 1.940 \\
Entire Emotional Exhaustion & $16.290^{* * *}$ & $7.798^{* *}$ & $6.355^{* * *}$ & $10.803^{* * *}$ & $13.340^{* * *}$ \\
\hline
\end{tabular}

$* \mathrm{p}<0.05$ significant level; $* * \mathrm{p}<0.01$ extraordinary significant level; $* * * \mathrm{p}<0.001$ absolutely significant level

Table 3. Abstract of the analysis on the correlation between emotional labor and the spectrum of the aspects of emotional exhaustion $(\mathrm{N}=353)$

\begin{tabular}{|c|c|c|c|c|c|c|c|}
\hline & 1. & 2. & 3. & 4. & 5. & 6. & 7. \\
\hline \multicolumn{8}{|l|}{ 1. Spectrum of Emotional Labor } \\
\hline 2. Basic Emotional Expression & $0.839 * *$ & & & & & & \\
\hline 3. Surface Acting & $0.751 * *$ & $0.625 * *$ & & & & & \\
\hline 4. Deep Acting & $0.765 * *$ & $0.501 * *$ & $0.528 * *$ & & & & \\
\hline 5. Multiformity & $0.338 * *$ & 0.032 & $0.110^{*}$ & $0.114 *$ & & & \\
\hline 6. Interaction & $0.729 * *$ & $0.624 * *$ & $0.416 * *$ & $0.412 * *$ & $0.222 *$ & & \\
\hline 7.Entire Level of Emotional Exhaustion & $0.256 *$ & $0.138^{* *}$ & $0.138 * *$ & $0.371 *$ & -0.055 & $0.211 * *$ & \\
\hline
\end{tabular}

Data source: Integrated by this research; * $\mathrm{P}<0.05 ; * * \mathrm{P}<0.01$ (Single tail)

Marriage: The deep acting of single flight attendants was more pronounced than that of married flight attendants. Additionally, the emotional exhaustion of flight attendants who selected the term "other" to describe their marital status was stronger than that reported by married flight attendants.

Educational background: The feeling of emotional exhaustion among flight attendants who had masters degrees was greater than among those who had graduated from high school, junior college, or college.

Service years: Flight attendants who had served for three to seven years reported stronger feelings of emotional exhaustion than did those who had served fewer than three years. Correlatively, the feeling of emotional exhaustion reported by flight attendants who had served more than 15 years was more pronounced than that reported by flight attendants who had served for three to 11 years.

Average salary: Flight attendants with an average salary of NTD90-100,000 expressed more marked feelings regarding the overall level of emotional labor than did flight attendants with an average salary of NTD60-90,000. Feelings regarding the basic emotional expression expected of flight attendants with an average salary of NTD90-100,000, in turn, were more marked than those expressed by those with an average salary of NTD80-90,000. Feelings of engaging in deep acting were stronger among flight attendants with an average salary of NTD90-100 than among those whose average salary was less than NTD60,000. Finally, feelings about emotional exhaustion expressed by flight attendants whose average salary was NTD90-100,000 were stronger than those reported by flight attendants with an average salary of less than NTD60,000, and those with an average salary of NTD60-90,000.

In combination, these results indicate that flight attendants from different backgrounds have significantly different experiences regarding emotional labor and emotional exhaustion. Thus, Hypothesis 1 and Hypothesis 2, which posited that existence of such differences in experience based on background variables, are both partially supported.

Referring to Table 3, the measure of overall emotional labor showed a significant positive correlation with each element $(\mathrm{P}<0.01)$ within the emotional labor measure, and the score for overall emotional labor showed a significant positive correlation with emotional exhaustion $(p<0.05)$. Among the elements of emotional labor, only deep acting showed a significant positive correlation with emotional exhaustion $(\mathrm{p}<0.05)$. The other elements did 
Table 4. Abstract of the stepwise multiple regression analysis on each aspect of emotional labor for emotional exhaustion $(\mathrm{N}=353)$

\begin{tabular}{|c|c|c|c|c|c|c|}
\hline $\begin{array}{c}\text { Selective Sequence of } \\
\text { Variables }\end{array}$ & $\begin{array}{l}\text { Multiple Correlation } \\
\text { Coefficient }(\mathrm{R})\end{array}$ & $\begin{array}{l}\text { Determination } \\
\text { Coefficient }\left(\mathrm{R}^{2}\right)\end{array}$ & $\begin{array}{c}\mathrm{R}^{2} \text { after } \\
\text { Regulation }\end{array}$ & F Value & $\begin{array}{l}\text { Original Regression } \\
\text { Coefficient }(\beta)\end{array}$ & $\begin{array}{c}\text { Standardized Regression } \\
\text { Coefficient }\end{array}$ \\
\hline Intercept (Constant Term) & & & & & 2.526 & \\
\hline Deep Acting & 0.371 & 0.137 & 0.135 & $55.871 * * *$ & 0.380 & $0.382 * * *$ \\
\hline Multiformity & 0.383 & 0.147 & 0.142 & $30.141 * * *$ & -0.081 & $-0.099 *$ \\
\hline
\end{tabular}

$* \mathrm{p}<0.05$ significant level; *** $\mathrm{p}<0.001$ absolutely significant level

not reach significance. The correlations among these perspectives are described as follows:

The score for overall emotional labor showed a significant positive correlation with each element of emotional labor $(\mathrm{P}<0.01)$. Furthermore, overall emotional labor showed a significant positive correlation with overall emotional exhaustion $(\mathrm{p}<0.01)$. Among the elements of emotional labor, only multiformity failed to show a significant correlation with emotional exhaustion $(\mathrm{r}=$ $-0.055, \mathrm{p}=0.15>0.05$ ); the other elements of emotional labor all showed significant correlations with emotional exhaustion. Finally, the overall measure of emotional labor showed a significant positive correlation with the overall measure of emotional exhaustion. Thus, Hypothesis 3 , which predicted just such a relationship, was also supported.

Referring to the stepwise multiple regression analysis shown in Table 4, the two perspectives labeled deep acting and multiformity (from among the five elements of emotional labor) predicted criterion variables in the regression model. The multiple correlation coefficient, R, was 0.383 , and its united explanation variance was 0.147 , indicating that these two variables explain $14.7 \%$ of the entire emotional exhaustion measure. Referring to the results above, deep acting and multiformity have significant positive and negative predictive capability for emotional exhaustion, respectively. Therefore, Hypothesis 4, which posited that flight attendants' emotional labor would have a significant predictive effect on emotional exhaustion, was also partly supported.

\section{Conclusions}

Referring to Table 1, it appears that domestic flight attendants' feelings about emotional labor can be described using a 5-point Likert scale, with the average score being 4.15. Thus, flight attendants' average feeling about the role of emotional labor in their lives is moderately strong. This result indicates that flight attendants can be classified as workers who engage in a high level of emotional labor. Regarding feelings about various forms of emotional labor, the element of emotional labor having to do with interaction showed the strongest effect in the present findings. Compared to colleagues in other departments, flight attendants had face to face contact with clients, and had conversations for longer periods, and with higher frequency. Therefore, flight attendants are also first-line service people in the airline industry [1]. Adleman's research [18] mentioned that worker performance and satisfaction were lower among those engaging in high levels of emotional labor than among workers with less emotional labor. High levels of emotional labor can easily generate feelings of unhappiness, lack of self-respect, and depression. Therefore, aviation management organizations must consider whether long-term emotional labor will have negative emotional effects on flight attendants.

Flight attendants' feelings about emotional exhaustion can also be described using a 5-point Likert scale, with an average score of 3.81. This indicates that, on average, flight attendants in this study experienced a moderate level of emotional exhaustion. More specifically, examination of the detailed questions regarding emotional exhaustion revealed that the highest average score was given to the statement, "The whole work day makes me feel tired." this was followed in importance by the statement, "My work makes me feel tired emotionally." Thus, most flight attendants reported that they felt tired when working for a long period of time. This research highlights the consequences of the tiring nature of flight attendants' working environment. Take offs and landings are frequent for domestic airlines, which means that flight attendants must repeatedly provide customer service. Thus, it is easy for flight attendants to feel that their work is dull and repetitive. Flight attendants serving international airline routes have to face a variety of passengers with distinctive needs; thus, the company is stricter about the entire range of services. All of these factors contribute to flight attendants' feelings of exhaustion when working for a long period of time.

Referring to Table 2, findings addressing differences among flight attendants with different background variables and the relationships of these variables to emotional labor and emotional exhaustion indicate that all background variables play a role. Relationships between emotional labor and variables of age, marital status, service years, and average salary all reached significance. Flight attendants with longer service years have deeper feelings 
about emotional labor. This may be because service year is directly related to a particular level of customer service. New attendants may mainly serve in economy class, those with intermediate service years may serve business class, and those with the most service years may work in first class. Because the passengers in first class have high social status, the flight attendants must be especially attentive; they have to concentrate on their movements, emotional expressions, and so on. Therefore, we suggest that this is the reason that flight attendants with longer service years have deeper levels of emotional labor.

For feelings of emotional exhaustion among flight attendants with different population backgrounds, relationships between emotional exhaustion and the population variables of age, marital status, educational background, service years, and average salary all achieved significance. As regards educational background, our findings indicate that the higher the educational background of the flight attendant, the higher are the requirements for their work performance. Cordes and Dougherty [10] pointed out that high work achievement motivation and serious attention to work can result in high stress and can easily generate emotional exhaustion.

For the relationship between domestic flight attendants' emotional labor and emotional exhaustion, overall emotional labor scores showed a significant positive correlation with emotional exhaustion. This means that the stronger the feelings about emotional labor, the higher the emotional exhaustion. As regards the predictive effect on emotional exhaustion of the various elements of emotional labor, deep acting had the strongest value for predicting emotional exhaustion. This means that the stronger the feeling about emotional labor, the higher the level of emotional exhaustion. In particular, when flight attendants realize that the company always responds to customer complaints by supporting the client rather than the employee, the degree of deep acting is likely to increase. Therefore, airlines should consider carefully how to decrease their employees' feeling that they must engage in deep acting; they should also consider more carefully their treatment of employees, and whether they should be more understanding and tolerant of employees.

\section{REFERENCES}

[1] S. J. Yuan, "The steward obeys the positive research of hardworking ability and passenger's satisfaction dependence," Department of Marketing and Distribution Management National Kaohsing First University of Science and Technology Master's thesis, 2005.
[2] H. C. Beh and P. McLaughlin, "Effect of long flights on the cognitive performance of air crew," Perceptual and Motor Skills, Vol. 84, pp. 319-322, 1997.

[3] S. C. Liang and A. T. Hsieh, "Burnout and workplace deviance among flight attendants in Taiwan," Psychological Reports, Vol. 101, pp. 457-468, 2007.

[4] A. R. Hochschild, "The managed heart: Commercialization of human feeling," Berkley, University of California Press, 1983.

[5] A. S. Wharton, "The affective consequences of service work: Managing emotions on the job," Work and Occupations, Vol. 20, No. 2, pp. 205-232, 1993.

[6] E. Goffman, "The Presentation of self in everyday life, Doubleday and Co," New York, NY, 1959.

[7] J. A. Morris and D. C. Feldman, "The dimensions, antecedents, and consequences of emotional labor," Academy of Management Review, Vol. 21, No. 4, pp. 986-1010, 1996.

[8] M. J. Morris and D. C. Feldman, "Managing emotions in the workplace," Journal of Managerial Issues, Vol. 9, No. 1, pp. 257-274, 1997.

[9] M. J. Saxton, J. S. Phillips, and R. N. Blakeney, "The changing nature of work," San Francisco: Jossey-Bass, pp. 365-410, 1991.

[10] C. L. Cordes and T. W. Dougherty, "A review and integration of research on job burnout," Academy of Management Review, Vol. 18, No. 4, pp. 621-656, 1993.

[11] S. E. Jaskson, R. Schwab, and R. S. Schuler, "Toward an understanding of the burnout phenomenon," Journal of Applied Psychology, Vol. 71, No. 1, pp. 630-640, 1986.

[12] C. Maslach, "Burnout: The cost of caring," Englewood Cliffs, NJ: Prentice-Hall, 1982.

[13] C. Maslach and S. E. Jackson, "Maslach burnout," San Francisco, CA: Jossey-Bass, 1986.

[14] A. Rafaeli and R. I. Sutton, "The expression of emotion in organizational life," Research in Organizational Behavior, Vol. 11, No. 1, pp. 1-42, 1989.

[15] L. C. Wang, "Role's pressure influences the course discussion that mood exhausts," Department of Business Administration, Institute of Behavior Medicine, National Cheng Kung University, Master's thesis, 1999.

[16] S. P. Lin, "Organize the development of the form of amount of load of labor service of mood," Sun Yat-Sen Management Review, Vol. 8, No. 3, pp. 427-447, 2000.

[17] C. Maslach and M. P. Leiter, "The truth about burnout," San Francisco, CA: Jossey-Bass, 1997.

[18] P. K. Adelmann, "Emotional labor and employee well-being," Doctoral Dissertation, The University of Michigan, 1989. 